This PDF is a selection from an out-of-print volume from the National Bureau of Economic Research

Volume Title: Evaluation of Econometric Models

Volume Author/Editor: Jan Kmenta and James B. Ramsey, eds.

Volume Publisher: Academic Press

Volume ISBN: 978-0-12-416550-2

Volume URL: http://www.nber.org/books/kmen80-1

Publication Date: 1980

Chapter Title: Relevance of Laboratory Experiments to Testing Resource Allocation Theory

Chapter Author: Vernon L. Smith

Chapter URL: http://www.nber.org/chapters/c11710

Chapter pages in book: (p. 345 - 377) 


\title{
Relevance of Laboratory Experiments to Testing Resource Allocation Theory
}

\author{
VERNON L. SMITH \\ DEPARTMENT OF ECONOMICS \\ UNIVERSITY OF ARIZONA \\ TUCSON, ARIZONA
}

\section{Introduction}

Microeconomics, including the study of individual choice and of group choice in market and nonmarket processes, has generally been considered a field science as distinct from an experimental science. Hence microeconomics has sometimes been classified as "nonexperimental" and closer methodologically to meteorology and astronomy than to physics and experimental psychology (Marschak, 1950, p. 3; Samuelson, 1973, p. 7). But the question of using experimental or nonexperimental techniques is largely a matter of cost, and generally the cost of conducting the most ambitious and informative experiments in astronomy, meteorology, and economics varies from prohibitive down to considerable. The cost of experimenting with different solar system planetary arrangements, different atmospheric conditions, and different national unemployment rates, each under suitable controls, must be regarded as prohibitive. On a more feasible scale, cloud-seeding experiments, Jupiter-Saturn scientific space probes, and field experiments in negative income taxes and education vouchers, while costly, are not prohibitive. But these more grandiose experiments are of recent occurrence, and basic scientific development in the cases of astronomy and meteorology has depended upon small-scale laboratory experiments in the physics of mass motion, thermodynamics, and nuclear reactions.

In this paper we try to develop a foundation for the study of resource allocation mechanisms entirely in terms of propositions that are testable, and 
tested, by means of controlled laboratory experiments. The question implicit throughout the paper is What can we, and do we, know with high credibility about allocative mechanisms? The statement "high credibility" means that the propositions have been tested under controls that can be evaluated and scrutinized, and the results replicated, by other researchers. Specifically, we can reject the hypothesis that the researcher and his subjects are themselves a significant treatment variable and become as sure as we please of the propositions by repeated replication. Although the measurement and verification of hypotheses about individual behavior, e.g., Slutsky-Hicks demand theory (Battalio et al., 1973), are of coequal importance in experimental economics, the discussion here will be limited to experimental studies of resource allocation mechanisms.

\section{Some Preceptual Foundations of Experimental Economics}

Three precepts are offered to constitute a foundation for the use of laboratory experimental methods in testing hypotheses about the behavior of allocation mechanisms. ${ }^{1}$

Precept 1: Nonsatiation (Smith, 1976a). Given a costless choice between two alternatives which differ only in that the first yields more of the reward medium (e.g., currency) than the second, the first will always be chosen (preferred) over the second by an autonomous individual, i.e., utility $U(M)$ is a monotone increasing function of the reward medium.

In credible economics experiments real people must make real decisions about objects or activities that have real value. Since control is the essence of experimental methodology, it is critically important that the experimenter be able to control or specify individual values to a degree that allows one to state that as between two experiments individual values either do or do not differ in a specific way. Precept 1 allows such control to be achieved by using a reward structure to induce value on the objects traded, or the actions taken, in a particular experimental setting.

EXAmple 1. The simplest example of the application of Precept 1, and one that is used frequently in market mechanism experiments, is that of inducing a demand for units of an abstract commodity. Let subject buyers, $i=1,2, \ldots, n$, each be given a function (in graphical or tabular form) listing increasing concave currency receipts $R_{i}\left(q_{i}\right)$ to be provided by the experi-

\footnotetext{
${ }^{1}$ Also see Fiorina \& Plott (1975) and Plott (1978) for further discussion of methodological aspects of laboratory decision experiments.
} 
menter for $q_{i}$ units purchased in an experimental market. Neoclassical demand is defined as the set of alternative quantities that would be purchased contingent upon corresponding given prices prevailing in the market. Assuming differentiability, at price $p$ the utility to $i$ of purchasing $q_{i}$ units is $U_{i}\left[R_{i}\left(q_{i}\right)-p q_{i}\right]$, which is a maximum for $q_{i}>0$ if and only if $\left[R_{i}^{\prime}\left(q_{i}\right)-p\right]$ $U_{i}^{\prime}[\cdot]=0$ for $U_{i}$ concave in $q_{i}$. Since $U_{i}^{\prime}>0$, the $i$ th individual induced demand is $q_{i}=R_{i}^{\prime(-1)}(p)$. Hence the induced market demand for $n$ individuals is $Q=\sum_{i=1}^{n} R_{i}^{(-1)}(p)$.

EXAMPLE 2. Subject agents are each given a function (in graphical or tabular form) listing quasi-concave total currency receipts, $V^{i}\left(y_{i}, X\right)$ to be paid to $i$ if $i$ retains $y_{i}$ units of a private good and the collective of agents agrees on the quantity $X$ of a public good. Then i's unknown utility for money $U_{i}(\cdot)$ induces the utility $U_{i}\left[V^{i}\left(y_{i}, X\right)\right]$ on any point $\left(y_{i}, X\right)$. Induced on each subject is the experimentally controlled indifference map given by the level contours of $V^{i}\left(y_{i}, X\right)=$ constant, independent of a particular subject's utility of money. That is, each $i$ 's marginal rate of substitution of $y_{i}$ for $X$ is given by

$$
\frac{d y_{i}}{d X} \equiv-\frac{U_{i}^{\prime} V_{2}^{i}}{U_{i}^{\prime} V_{1}^{i}}=-\frac{V_{2}^{i}}{V_{1}^{i}}, \quad \text { if } \quad U_{i}^{\prime}>0 .
$$

It is assumed that $V^{i}$ is increasing in $y_{i}$ for all $i$, but $V^{i}$ could be increasing or decreasing in $X$ depending on whether $X$ is a "good" or a "bad" for any particular agent. The experimenter need not be constrained to impose the condition that the common outcome variable $X$ be a good for every agent.

It might be supposed that using currency to induce value on abstract experimental choices is an artificial procedure peculiar to the methodology of laboratory decision studies. But this interpretation is incorrect. Economic systems produce countless examples of intangible property on which value is induced by virtue of the specification of conditions under which the holder of the intangible item may claim money or goods. All financial instruments such as shares, bonds, options, futures contracts, and indeed fiat money itself have value induced upon the instruments by the bundle of rights they convey. Experimental instructions define the rights of subject agents, and specify the institutions of decision making in the experiment. In Example 1, subject buyer $i$ is given the unabridged right to claim $R_{i}\left(q_{i}\right)$ units of money (less any specified costs) from the experimenter in return for the acquisition of $q_{i}$ units of "commodity" under the trading rules of the exchange institution. Without such a right a subject need have no more motivation to purchase the experimental commodity than would an investor who had no claim to the earnings and assets of Chrysler Corporation as a result of purchasing the company's stock. 
At least three important qualifications to the theory of induced valuation based upon Precept 1 must be recognized because these qualifications constitute potential pitfalls to the routine, casual, or mechanical interpretation of experimental results. These qualifications stem from the adjectives "costless" and "autonomous" in the statement of Precept 1 and will be summarized in the following precept.

Precept 2: Complexity. In general individual decision makers must be assumed to have multidimensional values which attach nonmonetary subjective cost or value to (1) the process of making and executing individual or group decisions, (2) the end result of such decisions, and (3) the rewards (and perhaps behavior) of other individuals involved in the decision process.

This precept covers the phenomenon of subjective transaction cost or the cost of thinking, calculating, and acting (cf. Marschak, 1968), the possible commodity value of decision outcomes, and interpersonal utilities. Since the subjects in an economics experiment are a sample drawn from the socioeconomic system, they can be expected to exhibit the behavioral characteristics of economic agents in that system.

One such characteristic is the attachment of subjective cost (or value) to the making and execution of market or other social decisions. In an auction market experiment a subject may find it arduous to monitor quotations, make his own quotations, and execute transactions. In a voting experiment a subject may see the process of agenda discussion, thinking about alternatives, and voting as toilsome activities. If such considerations are not negligible, they may be an important source of uncontrolled individual valuation of actions. Hence the utility function for $i$ becomes $U^{i}(M, E)$ where $M$ is monetary reward, and $E$ is the "transactional effort" required to obtain this reward (cf. Leibenstein, 1976, for an analysis of the effect of such nonmonetary disutilities on traditional microeconomic theory). If $E$ depends on the level of the rewarded activity, such as $q_{i}$ in Example 1, then there is some inevitable loss of control over the value induced on that activity. This is why a very small transaction commission is usually paid in auction market experiments, and why one tries to design experiments so that the reward is large relative to the mechanical complexity of the decision task (see Smith (1976a)). In the strict sense such nonmonetary utilities or disutilities give rise to a fundamental "principle of indeterminacy" of induced value ${ }^{2}$ although practically, at least in many laboratory experiments, the problem can be finessed by simple experimental design procedures.

\footnotetext{
${ }^{2}$ That is, we use a reward medium to induce gross value, but net value is indeterminant because we do not observe the subjective costs of transaction, decision and calculation that are implicit in the task.
} 
As with their counterparts in the economy, experimental subjects may attach subjective "game value" to experimental outcomes. Thus a makebelieve profit $R_{i}\left(q_{i}\right)-p q_{i}$ may have subjective value $S_{i}\left[R_{i}\left(q_{i}\right)-p q_{i}\right]$. If $S_{i}$ is monotone increasing, then such gaming utilities create no methodological problems since they reinforce rather than distort the effect of an explicit monetary reward structure. Using instructions to induce role-playing behavior (i.e., acting as if profits were real) can be useful and informative, but the results are more likely to be sensitive to particular experimenters, subject groups, task complexity, and other sources of variability.

Another characteristic of economic agents, and therefore experimental subjects, is that they may not be autonomous own-reward maximizers. Interpersonal utility criteria may upset the theory of induced value as contained in Precept 1 by allowing equity, altruistic, or invidious comparisons to influence subjective realized value. This distorting interdependence is usually controlled satisfactorily by the condition of "incomplete information" (Fouraker \& Siegel, 1963) wherein subject monetary rewards are only known privately during an experiment. Since such rewards are for the purpose of inducing utility on outcomes, and such utility is not observable in economic agents, this privacy condition is relevant to capturing "realism" in most experimental designs.

It is natural and important to inquire as to the relevancy of the results obtained from laboratory experiments to the behavior of economic agents in the economic system at large. This leads us to

Precept 3: Parallelism. Propositions about the behavior of individuals and of markets and other resource allocation mechanisms that have been tested in laboratory environments apply also to nonlaboratory environments where similar ceteris paribus conditions prevail.

This precept is not unique to social science but has relevance to all experimental methods.

We apply the term "parallelism" to the proposition suggested by Harlow Shapley (1964, p. 43) that "as far as we can tell, the same physical laws prevail everywhere." A science of astronomy or meteorology would scarcely have been possible without the maintained hypothesis that the physical laws of mass motion and the thermodynamics of gases, verifiable in small-scale laboratory experiments, had application to the stars and the climate. Furthermore, since nonexperimental measurements in astronomy and meteorology have not yet contradicted these physical laws, one has accepted this parallelism as having been confirmed.

This concept has important application to the study of microeconomic behavior. Two important research implications follow whenever replicable laboratory behavior has been firmly demonstrated. First, one should seek 
those extensions or modifications of existing theory that explain why it occurs, and second, one should seek field tests of the hypothesis that the behavior is also manifest in other, ostensibly "richer," environments. ${ }^{3}$ The robustness of a behavioral "law" across different environments can only be determined empirically. Theories normally abstract from all those characteristics which lead one to apply the adjective "richer" to a given environment, and hence represent statements about behavior that are hypothesized to be independent of the environment. But this indepencence hypothesis may not be correct, and by comparing behavior in different environments one may establish a basis for important extensions in theory.

Experiments are sometimes criticized for not being "realistic", i.e., parallelism is questioned. There are two appropriate responses to this criticism:First, if the purpose of the experiment is to test a theory, are the elements of alleged unrealism in the experiment parameters of the theory? If not, then the criticism must be directed to the theory as much as to the experiment. Laboratory experiments are normally as "rich" as the theories they test. Second, are there field data to support the criticism, i.e., data suggesting that there may be differences between laboratory and field behavior. If not, then the criticism is pure speculation; if so, then it is important to parametrize the theory to include the behavior in question.

What is important about an experiment is that it be relevant to its purpose, not that it be realistic in the sense that it be "real-world-like" in some subjective sense. Indeed, the best experiment is the crucial experiment whose outcome clearly distinguishes between competing theories. But the conditions of the crucial experiment may rarely, if ever, occur in nature.

For example, one of the crucial experiments of relativity theory is to determine if stars behind the edge of the sun appear to be displaced from their known positions during a total solar eclipse (i.e., whether or not light signals "bend" in gravitational fields). One does not object to such experimental observations because solar eclipses are not "realistic," i.e., not commonly observed; rather one marvels at this scientific exploitation of an unusual event. Similarly in particle physics, experimentalists synthesize unnatural conditions to produce particles predicted by theory but unobservable in the natural order. Fouraker \& Siegel (1963) have studied duopoly and triopoly price competition under the homogeneous product condition. This is "unrealistic" in the sense that such perfect oligopoly conditions are rarely, if ever, encountered in the field. A major Fouraker and Siegel finding-is a strong

\footnotetext{
${ }^{3}$ See Plott \& Levine (1974) for an interesting field experiment in the effect of agenda on majority rule group decision. Following the field experiment the authors designed similar laboratory experiments to test the replicability of their field results and to vary the agenda as a treatment variable in their model of group decision.
} 
tendency for triopolies and even duopolies to converge to the Bertrand competitive price solution. These results can be interpreted as providing an important explanation of why one so rarely observes homogenous product competition among the few. It is unprofitable; hence there are strong incentives for product differentiation. So is the experiment "unrealistic," or does it provide a relevant explanation of why the conditions of the experiment are not likely to survive in "nature"? How does one acquire an understanding of why institutions and their outcomes are as we observe them? I know of no way other than to experiment with alternative institutions and observe the consequent outcomes.

\section{Dynamic Market Adjustment Hypotheses}

Two sets of experiments designed to test hypotheses about the dynamic adjustment behavior of oral double auction markets are reported in this section.

\subsection{Two Experimental Markets with Growing Demand}

Hess (1972) has studied the effects of period-by-period changes in both supply and demand in an experimental double auction market. However, the subjects did not receive cash profit rewards, and as indicated above, this may affect outcomes in market experiments. The sequence of changed supply and demand was designed to create and reinforce the expectation that price rises a fixed amount (10 cents) each period. The effect of this expectation on the subsequent empirical observations was determined in each of four different experimental sessions. This price expectation "treatment" was found to bias actual prices away from their theoretical values.

Arrow (1960) and Arrow \& Capron (1959) have discussed price-quantity adjustments in competitive markets with rising demands. Assuming a linear demand function increasing linearly with time and a linear Walrasian adjustment process, Arrow proves several propositions briefly paraphrased as follows:

1. The shortage (defined as excess demand) increases from the initial value of 0 toward an asymptotic limit.

2. Prices rise, and the increase approaches a constant rate depending only on supply and demand conditions.

3. Actual price is always below the price that would clear the market. These propositions also hold under the hypothesis of adaptive expectations, i.e., where the economic agent compares actual price with his previous 
expectation of it and then forms a new expectation by revising his previous expectation in the direction of the actual price. ${ }^{4}$

Two experiments designed to approximate the conditions of the preceding propositions are used to test their validity. In each experiment demand rises linearly with time, where "time" is measured in terms of trading periods, and the experimental supply and demand conditions are approximately linear.

Twenty-seven subjects participated in the first experiment and fortyseven in the second. The instructions were those of the double auction (Smith, 1964, pp. 199-201 where both buyers and sellers are permitted to make oral quotations (bids or offers). Each buyer (seller) received a 5 cent commission in addition to the profit from exchange. Profit was equal to buyer value or limit price minus purchase price (for sellers, price minus cost).

Experiment 1 consisted of six trading periods. At the end of each of the first four trading periods the buyers' cards were collected, and a new set of buyer limit prices, corresponding to an increase in demand, were distributed randomly among the buyers. Consequently, the highest limit buyer in period 1 would not be, except by accident, the highest limit buyer in period 2. The first five trading periods were characterized by the five demand arrays exhibited on the left of Fig. 1. At the end of the fifth trading period the buyer limit cards were collected, just as in the previous periods, except that this time the new.cards that were distributed corresponded to a repeat treatment of the period 5 demand condition. Hence the subjects did not know at any time that the demand had increased in periods 2 through 5 , nor that it had not increased in the case of period 6 . They knew only what was obvious - that buyers were receiving new limit price cards. Subject information consisted only of their private limit prices, the sequence of verbal bids, offers, and contract prices that prevailed in each trading period.

Experiment 2 used approximately the same supply and demand conditions as in 1, except that seven trading periods were conducted with the six demand schedules shown on the left of Fig. 2. The first experiment used undergraduates at Stanford, the second used public school teachers in a summer program at Purdue.

The response of contract prices in experiments 1 and 2 is graphed on the right in Figs. 1 and 2. Contract prices tend to be equal to or below the theoretical equilibrium in the first three periods of each experiment. In experiment 1 (2), only one (three) of the fifteen contracts in periods 1 to 3 were above equilibrium. But in period 5 of experiment 1 only one contract is below the theoretical equilibrium, and in experiment 2 , period 6 , only three of thirteen

\footnotetext{
${ }^{4}$ See Arrow (1960, pp. 8-13) for a rigorous derivation of these propositions and their extension using adaptive (trend) expectations.
} 


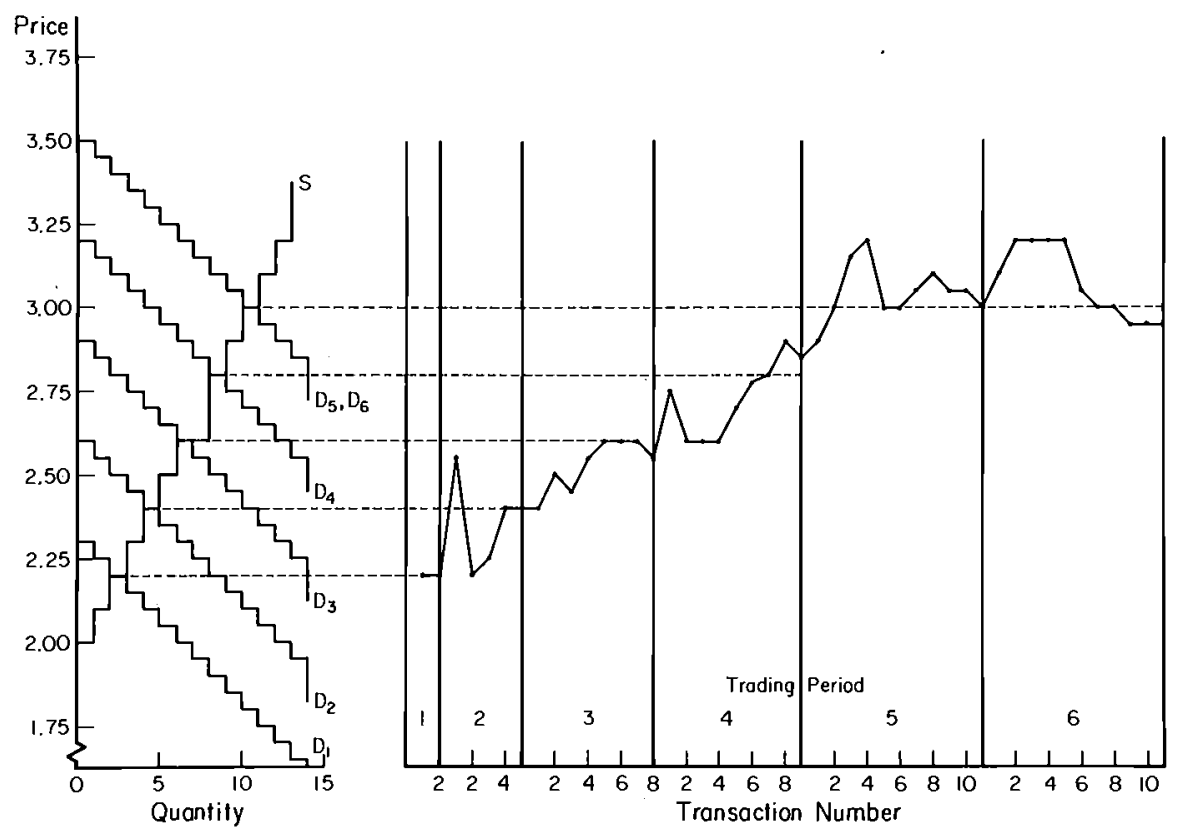

Fig. 1.

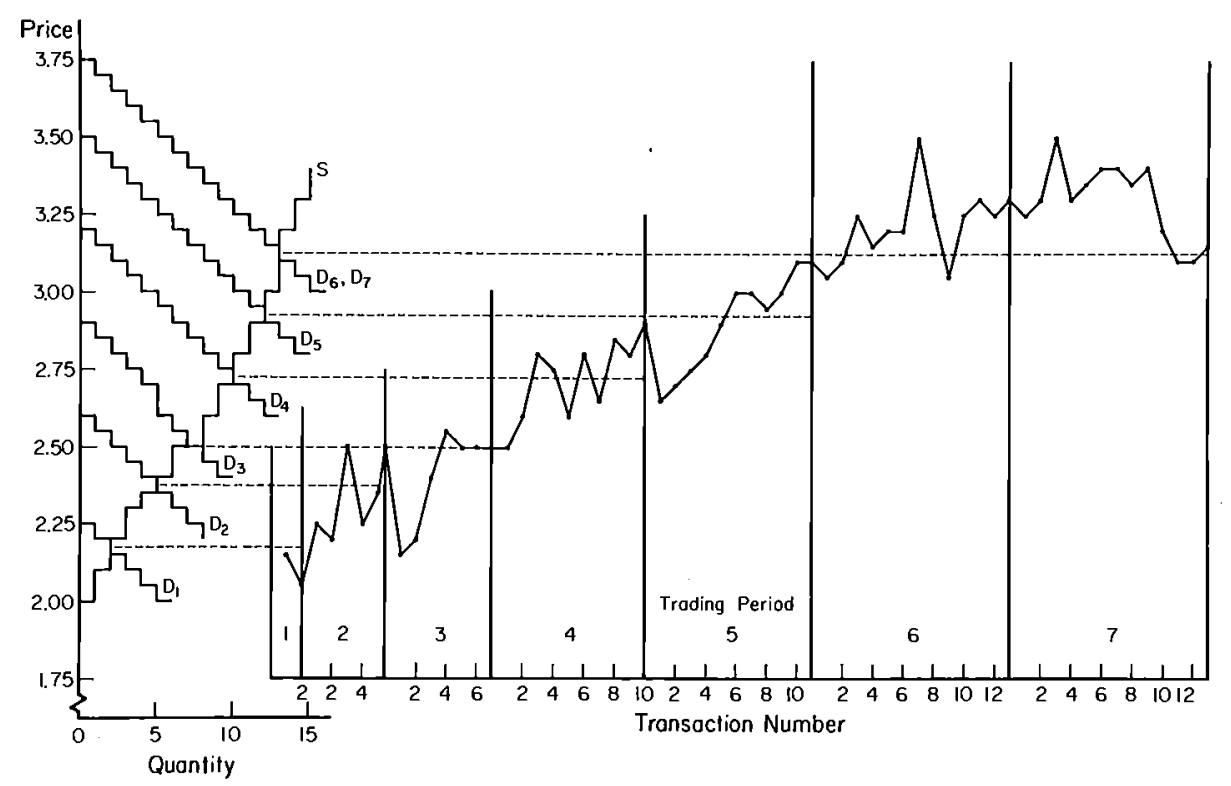

Fig. 2. 
TABLE 1

Price-Quantity Behavior with Growing Demand

\begin{tabular}{|c|c|c|c|c|c|c|c|c|}
\hline \multirow[b]{2}{*}{ Period } & \multicolumn{4}{|c|}{ Experiment 1} & \multicolumn{4}{|c|}{ Experiment 2} \\
\hline & $\begin{array}{c}\text { Theoretical } \\
\text { price }\end{array}$ & $\begin{array}{l}\text { Mean } \\
\text { price }\end{array}$ & $\begin{array}{c}\text { Increase } \\
\text { in mean } \\
\text { price }\end{array}$ & Shortage & $\begin{array}{c}\text { Theoretical } \\
\text { price }\end{array}$ & $\begin{array}{l}\text { Mean } \\
\text { price }\end{array}$ & $\begin{array}{c}\text { Increase } \\
\text { in mean } \\
\text { price }\end{array}$ & Shortage \\
\hline 1 & 2.20 & 2.20 & & 0 & 2.175 & 2.10 & & 2 \\
\hline 2 & 2.40 & 2.36 & .16 & 1 & 2.375 & 2.34 & .24 & 2 \\
\hline 3 & 2.60 & 2.53 & .17 & 2 & 2.50 & 2.40 & .06 & 4 \\
\hline 4 & 2.80 & 2.73 & .20 & 2 & 2.725 & 2.73 & .33 & 0 \\
\hline 5 & 3.00 & 3.05 & .32 & -1 & 2.925 & 2.90 & .17 & 0 \\
\hline 6 & 3.00 & & & & 3.125 & 3.22 & .32 & -3 \\
\hline 7 & & & & & 3.125 & & & \\
\hline
\end{tabular}

contracts are below equilibrium. Proposition 3 fails to be supported in period 5 of experiment 1 and period 6 of experiment 2 . Using a $t$ test on the contract prices in these two periods, we reject the hypothesis (Proposition 3) that the data came from populations with a mean equal to $\$ 3.00(t=2.86)$ in experiment 1 and equal to $\$ 3.125(t=2.81)$ in experiment 2 . In each experiment the experience of rising prices eventually produced expectations that caused sellers to raise their offers (and buyers to accept) above the theoretical equilibrium.

Evidence contrary to Proposition 1 is shown in Table 1. The "shortage" is interpreted, i.e., measured, as initial excess demand prevailing at the mean contract price. The proposition is violated in period 5 of experiment 1 and periods 4, 5, and 6 of experiment 2.

Also in Table 1 it is seen that the mean price rises in successive periods, but, at least for the limited number of periods observed, the increase in price does not appear to be approaching a constant ${ }^{5}$ (Proposition 2).

\subsection{SPeCulation and InTERTEMporal EQUilibrium}

Samuelson (1957) has provided an extension to intertemporal markets of the assumption sometimes made for stationary markets, that economic agents have "perfect" knowledge in the sense of foreknowledge of market supply and demand. Experiments such as those reported in the next sec-

${ }^{5}$ See Carlson (1967) for an experimental test of the cobweb theorem in dynamic markets with a lagged supply response. Carlson reports convergence in such markets even in the so-called "unstable" case. Both Carlson's experiments and those reported here suggest that conventional dynamic theory does not provide satisfactory models of price adjustment behavior. 
tion make it obvious that such assumptions are not necessary to yield convergence to competitive equilibria under the oral double auction exchange mechanism. A recent experimental study (Miller, Plott, \& Smith, 1977) has examined the hypothesis that, under incomplete information, speculation will narrow seasonal price differences significantly below the theoretical price differences in the absence of speculation. Williams (1977) has replicated this work and extended it to test the hypothesis that speculation will narrow actual, as well as theoretical, seasonal price differences.

In these two studies the intertemporal experimental paradigm is one in which (unknown to the subjects) demand cycles from $D_{\mathrm{b}}$ in the "blue" (B) season to $D_{y}$ in the "yellow" (Y) season in each period, while the supply $S$ is stationary from one season to the next. These demand and supply configurations are shown on the left of Figs. 3 and 4. Again the double oral auction price mechanism was used in each season of trading. Six buyers each had a capacity to buy two units at specified limit prices that were different in each season. These limit prices defined demands $D_{\mathrm{b}}$ and $D_{y}$ for up to twelve units per season as shown. Six sellers each had a capacity to sell two units at specified limit (cost) prices which did not differ between seasons. These limit prices defined the supply $S$ shown in Figs. 3 and 4.

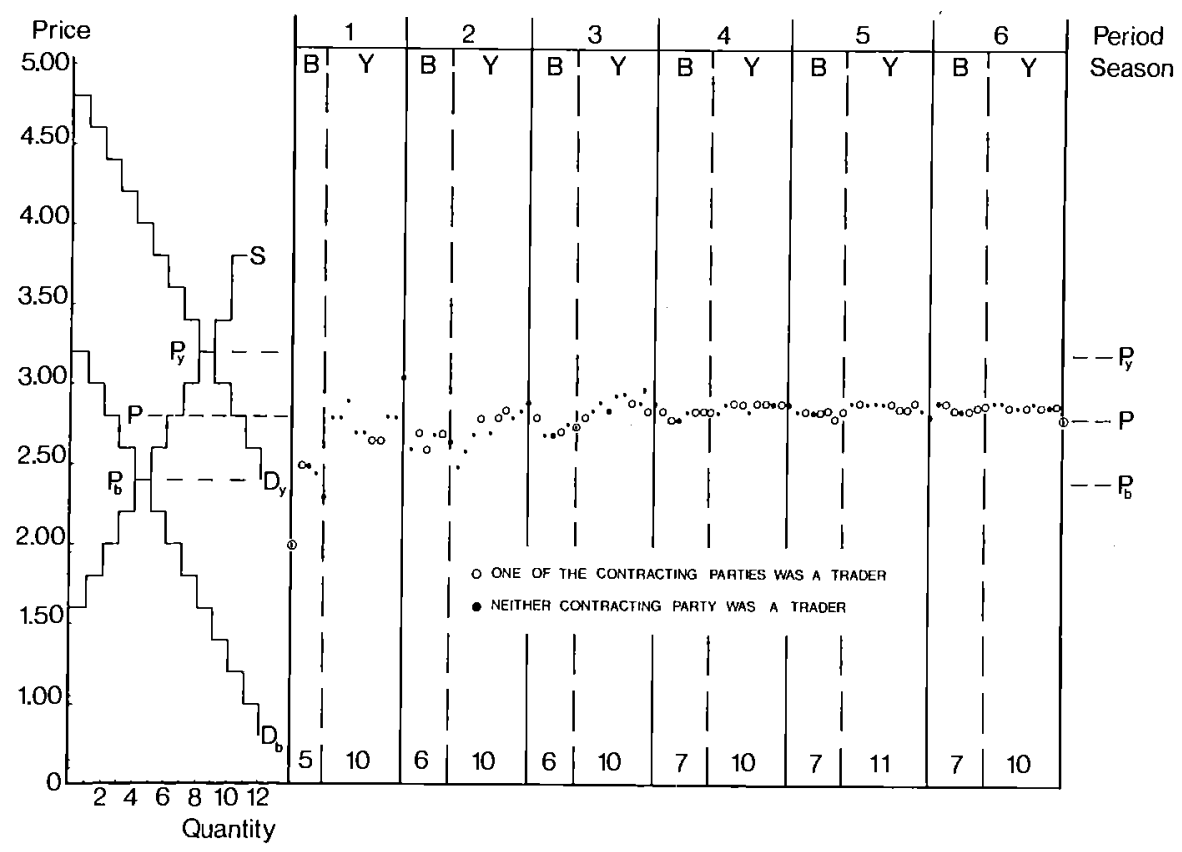

Fig. 3. [From Miller, Plott, \& Smith (1977).] 


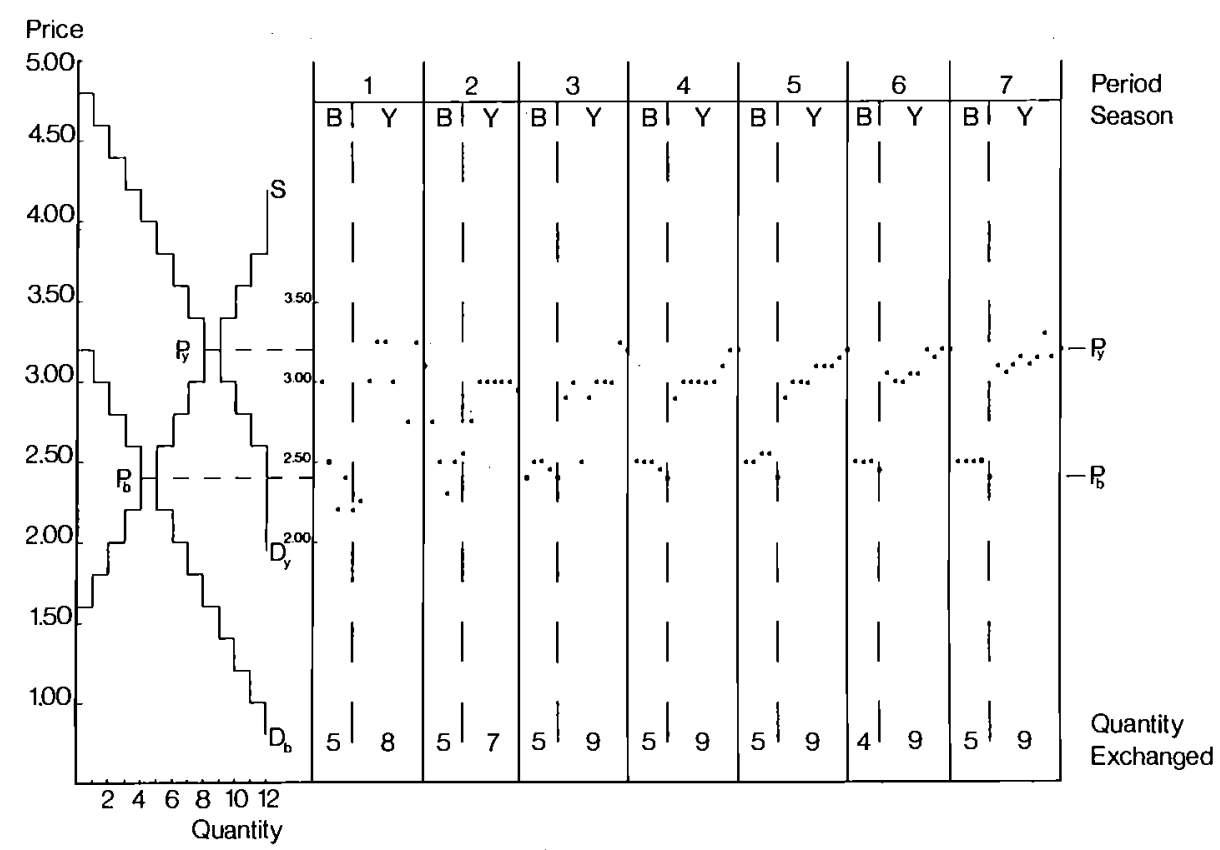

Fig. 4. [Reprinted from V. L. Smith (Ed.), Research in Experimental Economies, Volume 1, JAI PRESS INC., 1979.]

Finally, in each experiment two "traders" were given the power to buy any number of units in a B season. Any units thus purchased could be carried over (at zero cost) for resale only in the subsequent $Y$ season. Since it was possible for these traders to make losses they were each given a $\$ 3$ initial capital endowment. No subject had any information on market demand or supply, but all subjects could observe the bids, offers, and contracts as they occurred.

In Fig. 3 (from Miller et al. 1977), during period 1 two purchases were made by traders in $B$, and resold in $Y$. In periods 2 and 3 traders carried over three units, and in the subsequent periods they carried over five units. Effectively, market prices were very near the intertemporal equilibrium by period 3. The optimal trader carry-over was four units, but they consistently carried over five units in periods 4 to 6 . This was because in each of these periods at least one seller, able to make a profit at these prices, failed to negotiate a sale before the trading season ended (seasons were timed, 5 minutes in length). In each case either a seller quoted offers too high to be accepted, or the offer lost to another seller. This reduced effective supply in the yellow season and permitted the unit of excess demand to be filled in by a trader carrying over an additional unit. 
Williams (1977) replicated this experiment with different subjects, and obtained essentially the same results. He also designed and executed an autarky (i.e., no speculating traders participated) experiment with the same parameters and procedure. His results are reproduced in Fig. 4. Note the tendency of contract prices to lag behind the cyclical shifts in demand which is to be expected in view of the similar "hysteresis" effects in Figs. 1 and 2 for growing demand. But in successive trading periods the gap between contract prices widens. Comparing Figs. 3 and 4 it is clear that speculation is a significant treatment variable.

The null hypothesis that the prices observed in the $\mathrm{B}$ and $\mathrm{Y}$ seasons of the final trading period came from populations with means equal to the autarky prices in these seasons is tested with the $t$ statistic

$$
t\left(n_{1}+n_{2}-2\right)=\bar{p}_{\mathrm{y}}-\bar{p}_{\mathrm{b}}-\left(p_{y}^{*}-p_{\mathrm{b}}^{*}\right) / s \sqrt{\left(1 / n_{1}\right)+\left(1 / n_{2}\right)} .
$$

$\bar{p}_{i}$ is the sample mean of $n_{i}$ prices for $i=\mathrm{b}, \mathrm{y}$, and $p_{i}^{*}$ is the autarky price for $i=\mathrm{b}, \mathrm{y} . s^{2}$ is the pooled estimate of the population variance for the combined B and Y seasons. In the Miller, Plott, Smith experiment, $t=$ -59.8 , and in the Williams replication $t=-19.5$ both significant with better than a .001 confidence level. Williams (1977) compared his speculation market and autarky market mean prices giving $t=-10.72$. Consequently, the null hypothesis that "speculation" is an ineffective treatment variable is still rejected at better than a .001 level of confidence. In this sense we know with "high credibility" that speculation is effective in providing an intertemporal equilibrium.

\section{Effect of Information on Price Convergence in Competitive Markets}

One of the most prominent, replicable, empirical properties of the double auction competitive price mechanism is its rapid convergence to the supply and demand equilibrium under the condition of incomplete information, or privacy, where each agent knows only his own marginal valuation or marginal cost function (Smith, 1976b). It might be supposed that under complete information, where each agent is informed of the value and cost functions of other agents, market convergence would improve, or at minimum not be worse. As briefly reported earlier (Smith, 1976a, p. 278), there is at least one class of crucial experiments for which this proposition must be rejected, namely the class in which all the exchange surplus is obtained by the buyers (or sellers) at the equilibrium price. Precept 2 provides a possible explanation of why this is the case: when agents 
know each other's payoffs, it provides scope for interpersonal utility considerations to impinge upon behavior.

The supply and demand curves on the left of Figs. 5 and 6 have the characteristic that at the equilibrium price the entire exchange surplus of $\$ 1.10$ (plus a 5 cent "commission") per transaction is captured by the buyers. Sellers receive only the 5 cent commission. In Fig. 5 the excess supply for all feasible transaction prices is five units, while for Fig. 6 excess supply is eight units. The panels in each figure plot successive transaction prices for independent groups of subjects, i.e., no subject participated in more than one of the eight experimental sessions. In each figure the (a) and (b) experiments were conducted under the incomplete information condition, the (c) experiments applied complete information, and the (d) experiments applied incomplete information initially for two (or three)

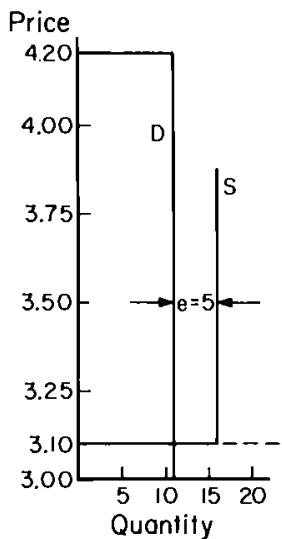

(o) INCOMPLE TE INFORMATION

(b) INCOMPLETE INFORMATION
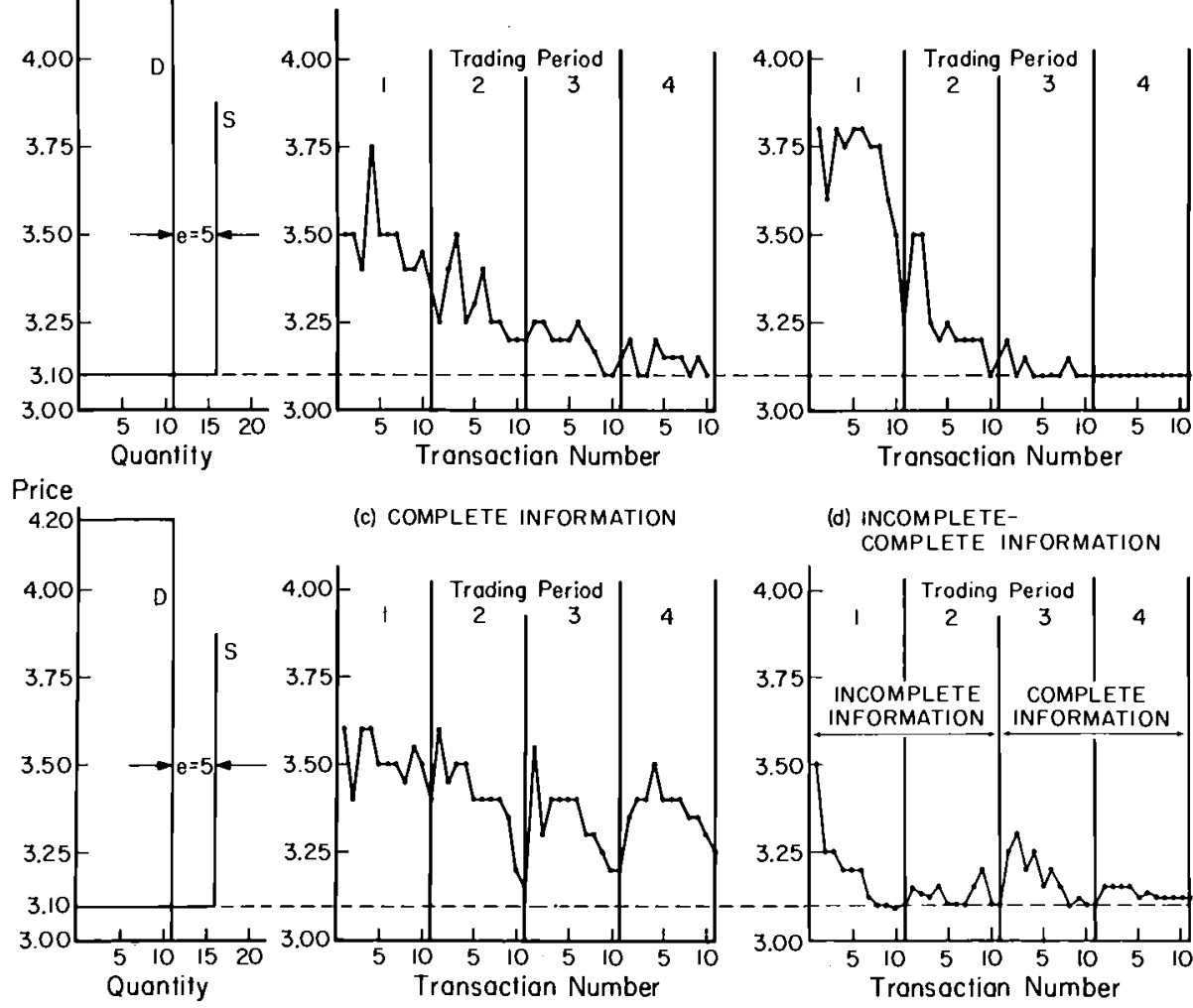

(c) COMPLETE INFORMATION

(d) INCOMPLETECOMPLETE INFORMATION
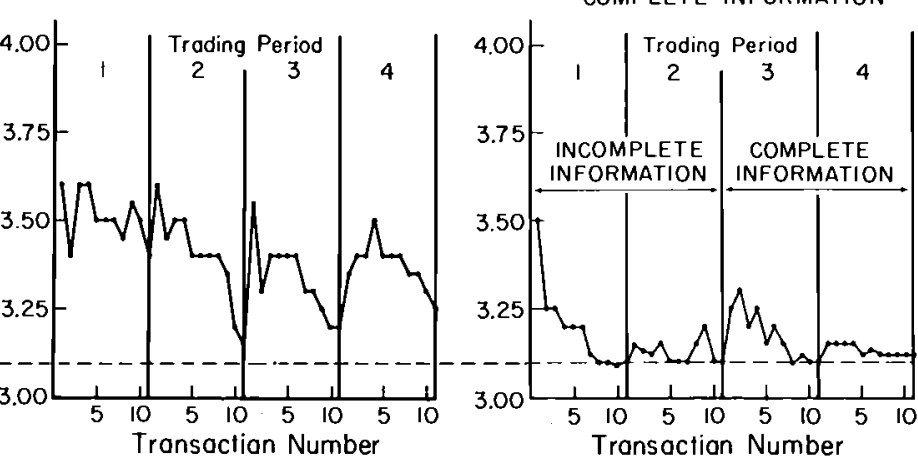

Fig. 5. 


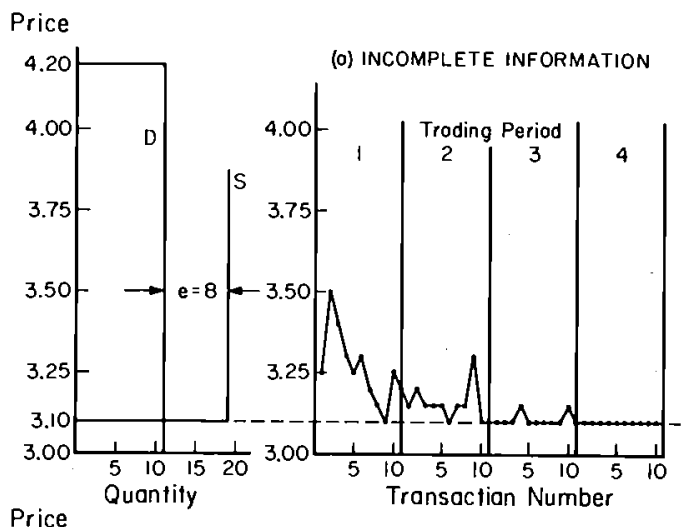

\begin{tabular}{l} 
Price \\
$4.20+$ \\
\hline
\end{tabular}

(b) INCOMPLETE INFORMATION
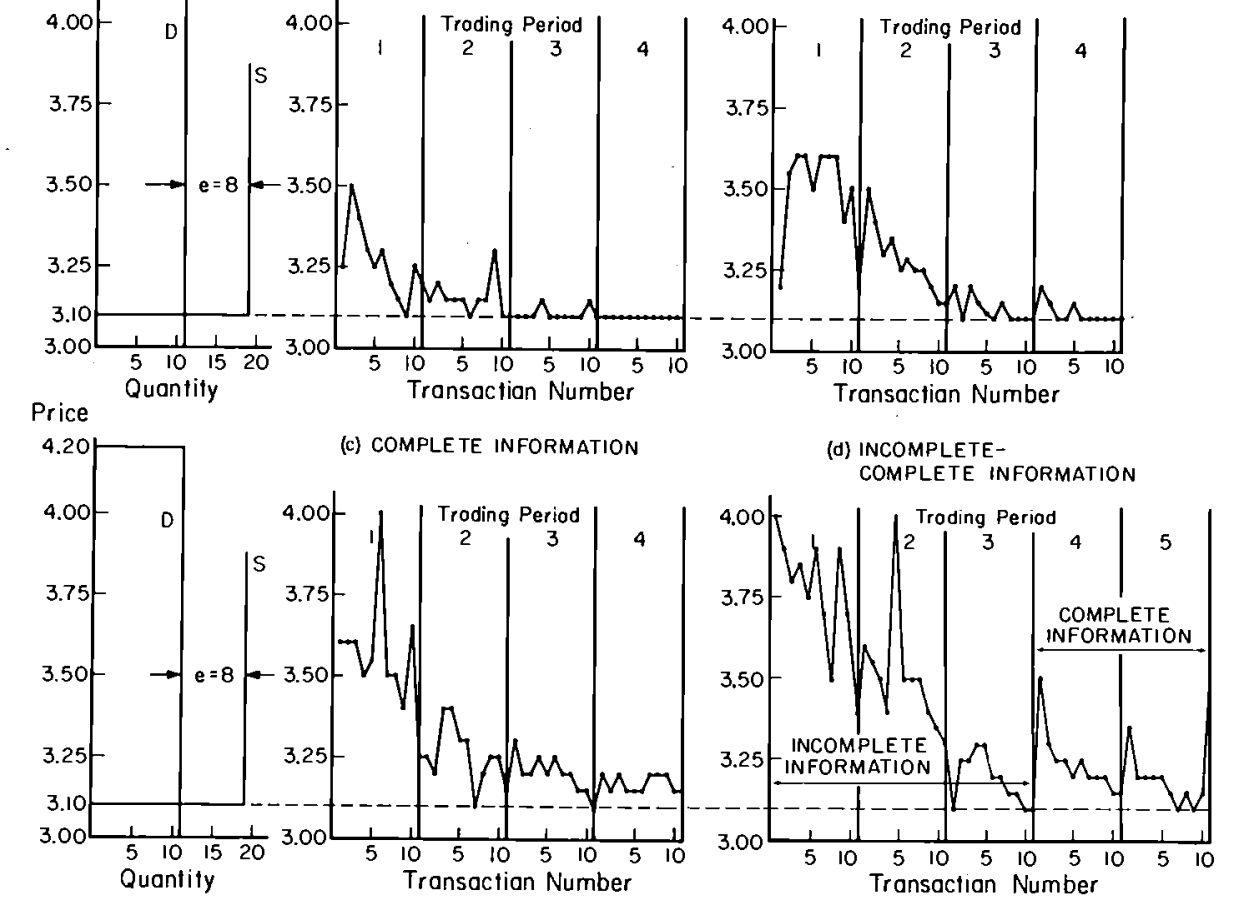

(d) INCOMPLETECOMPLETE INFORMATION

Fig. 6.

periods, then complete information was provided, and trading resumed for two additional trading periods. In all experimental sessions except 5(d) each subject could buy (or sell) one unit per trading period. In 5(d) there were three sellers, each of whom could sell six units per period, and two buyers who could buy five and six units respectively per trading period. Providing "complete information" meant informing all subjects that buyers each had limit prices $\$ 4.20$ and sellers $\$ 3.10$ and that up to 11 units could be purchased and up to 16 (19) units sold.

Comparing the results of the (a) and (b) experiments with those of (c), both Figs. 5 and 6 make it plain that convergence is more pronounced or more rapid in the incomplete than in the complete information treatments. That the differences are attributable to the treatment variable "information" is reinforced by the "switchover" experiments 5(d) and 6(d). In 5(d) introducing complete information after two periods of trading leads to a distinct "jump" in the level of contract prices, and similarly, in experiment 6(d) after three trading periods, complete information leads to an increase in 
the level of prices. But in each case the increase in prices is unable to persist in the final trading period as sellers compete to avoid forgoing sales.

Shubik (1959, pp. 169-170) long ago surveyed and incisively criticized what various authors have said about the alleged importance of "perfect knowledge" in driving competitive equilibria. Shubik's main point was that more information increases the likelihood that combinations will result. Although formal combinations were not allowed in the above experiments, a type of short-lived tacit collusion occurred under complete information which does indeed retard convergence to competitive equilibria.

\section{Sealed-Bid Mechanisms for Private Goods}

Sealed-bid auctions are an important and widely employed mechanism of exchange in construction, land, securities, and many other markets. This section will report on two previously unpublished experiments with sealedbid auctions, summarize some previously published experiments, and relate these earlier experiments to recent field experiments in the auctioning of new securites. These latter developments are especially significant in attempting to evaluate parallelism in bidding behavior as between laboratory and field environments.

\subsection{First, Second, and Seller Price Auctions}

When a unique indivisible commodity, such as a piece of land or a contract to build a bridge, is sold by sealed bidding, the rules normally call for the item to be awarded to the highest bidder at a price equal to the amount bid. Vickrey (1961) has suggested another rule, namely, that the item be awarded to the highest bidder at a price equal to the next highest bid. This rule is incentive compatible, or demand revealing, in that it is optimal for each bidder to enter a bid equal to his valuation (the maximum price he is willing to pay) for the item. This is because each buyer's surplus, if he is awarded the items, is independent of his bid provided that his bid is above that of the next highest bidder. Any bid below a buyer's actual valuation will therefore reduce the probability of the award, and be an inferior strategy. Marschak (see Smith (1979)) had suggested, prior to Vickrey's important contribution, a mechanism with the same property. Marschak's mechanism was to ask the seller to write down privately a "bid" for the item and put it in an envelope. The item is then awarded to the highest bidder provided the high bid exceeds that of the seller, otherwise the seller retains the item. This is equivalent to Vickrey's rule, since in effect the seller is being allowed to bid 
for his own item (which, by the way, is not permitted in some auctions). Marschak's rule has the advantage that it would apply even when there is only one buyer for the item. These three different mechanisms will be referred to as the first, second, and seller price auctions.

A pilot experiment was conducted as follows: each of six subjects bid on each of three auctioned "items," I, II, III, in each of 11 successive auction periods. The first period was a practice trial, while in each of the next ten periods the winning bidder on each item was paid the difference between that person's "resale" valuation price for the item and the price paid in that auction. Auction I was a first price auction, Auction II used the second price rule, while Auction III used Marschak's seller price rule. The subjects were naïve in the sense that they were not given any training or "coaching" on how one might bid. But ten "money" trials were run following the first trial with the idea of providing adequate scope for learning. The award rules for each of the three types of auctions were explained in written instructions, repeated verbally, and questions were answered. After the bids were collected in each period, the highest bid was posted on the blackboard for Auction I, the highest and second highest for Auction II, and the highest bid and the seller's bid for Auction III. The subjects' private "resale" valuations were chosen so that the highest value would be between $\$ 4$ and $\$ 9$, with the next highest subject valuation chosen at random among numbers that were $\$ .50, \$ 1.00$, and $\$ 1.50$ below the highest valuation for that auction. The remaining four valuations were chosen at arbitrary values lower than the second highest value.

Figure 7 plots by period the value - bid gap $\left(V_{i}-B_{i}\right)$, i.e., the difference between the resale value and the bid submitted by each subject for each auction. The above theory suggests the hypothesis that subjects will tend to bid so as to yield a higher $V_{i}-B_{i}$ in Auction I than in II or III. Ideally, according to the theory, subjects would bid their valuations in Auctions II and III so that $V_{i}-B_{i}=0$, but we expect real people to perceive this with differing degrees of error and perhaps exhibit some learning conditioned by experiences.

From Fig. 7 it will be observed that subjects 2,3,4, and 6 either perceived immediately, or learned within the first several trials, that it was in their interest to bid $B_{i}=V_{i}$ in Auctions II and III. Subject 5 did this in Auction III but not II. Since subject 5 happened to have the winning bid for Auction II on three occasions in spite of having bid $B_{5}<V_{5}$, no failure was experienced. Subject 1 is the only case of exceptionally slow learning if indeed it can be said that there was any learning.

The nonparametric paired-sample sign test was applied to the period-byperiod bids of all subjects comparing Auction I with Auction II bids. The null hypothesis that the bids in II are as likely to be above as below those in 

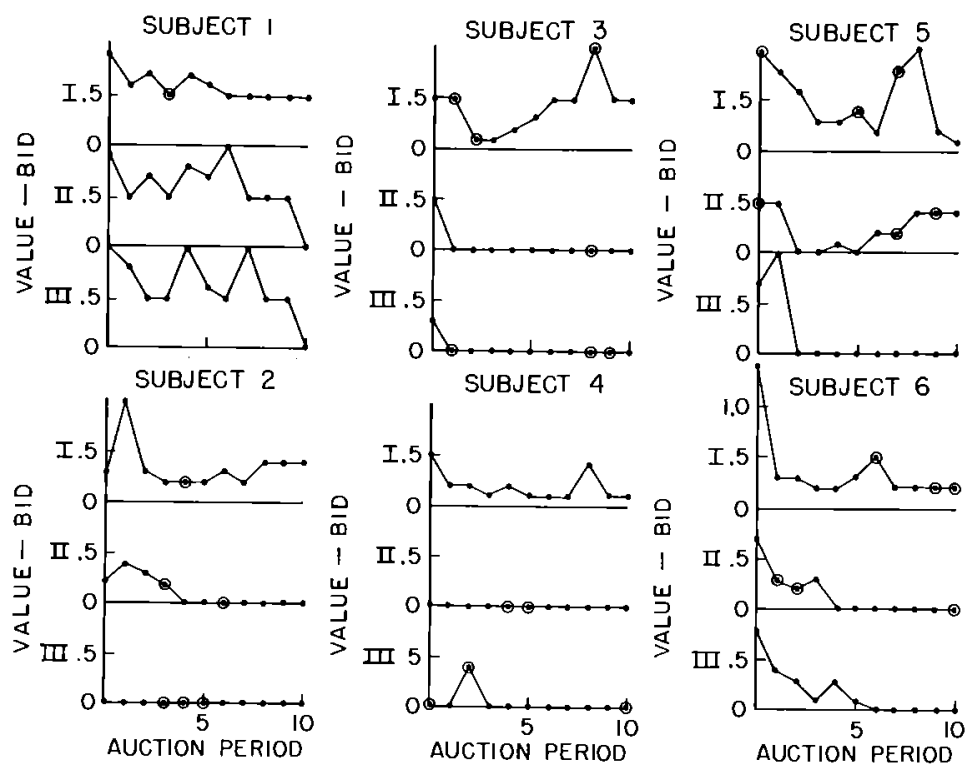

I First Price Auction
III Second Price Auction

Fig. 7.

I is tested against the one-sided alternative that the bids in II are above those in I. By this test the null hypothesis is rejected at a level of significance $p<.001$. Similarly, comparing Auction I with Auction III we reject the null hypothesis at $p<.001$.

\subsection{Sealed Bidding for Multiple Units: Monopoly Production}

Vickrey (1961) argues that some of the incentive characteristics of the First and Second Price auctions for a single item generalize to the case of multiple units offered for sale. When there are multiple units the analogue of the First Price auction has been called the discriminative auction (Smith, 1967) in which all accepted bids are filled at their respective bid prices. The analogue of the Second Price auction is the competitive or uniform-price auction wherein all accepted bids are filled at the lowest accepted bid price (Smith, 1967), or strictly, as noted by Vickrey, at the highest rejected bid price. But unless the offering is quite small one would not expect lowest accepted, versus highest rejected, bid rules to make more than an epsilon of behavioral difference. 
A pilot experiment was conducted using one subject as a monopoly producer and five subjects as buyers. The seller could produce up to twelve units at zero fixed cost and at marginal cost MC shown on the left of Fig. 8. Buyers each had marginal valuations for two units such that the five buyers together provided the demand $D$ shown in Fig. 8. Again the seller did not know the marginal valuations of any buyer and no buyer knew the valuations of other buyers nor the marginal cost situation of the seller. The theoretical monopoly price and quantity is $\left(P_{\mathrm{m}}, Q_{\mathrm{m}}\right)=(\$ 1.10,5)$, while the competitive is $\left(P_{\mathrm{c}}, Q_{\mathrm{c}}\right)=$ $(\$ .80,8)$.

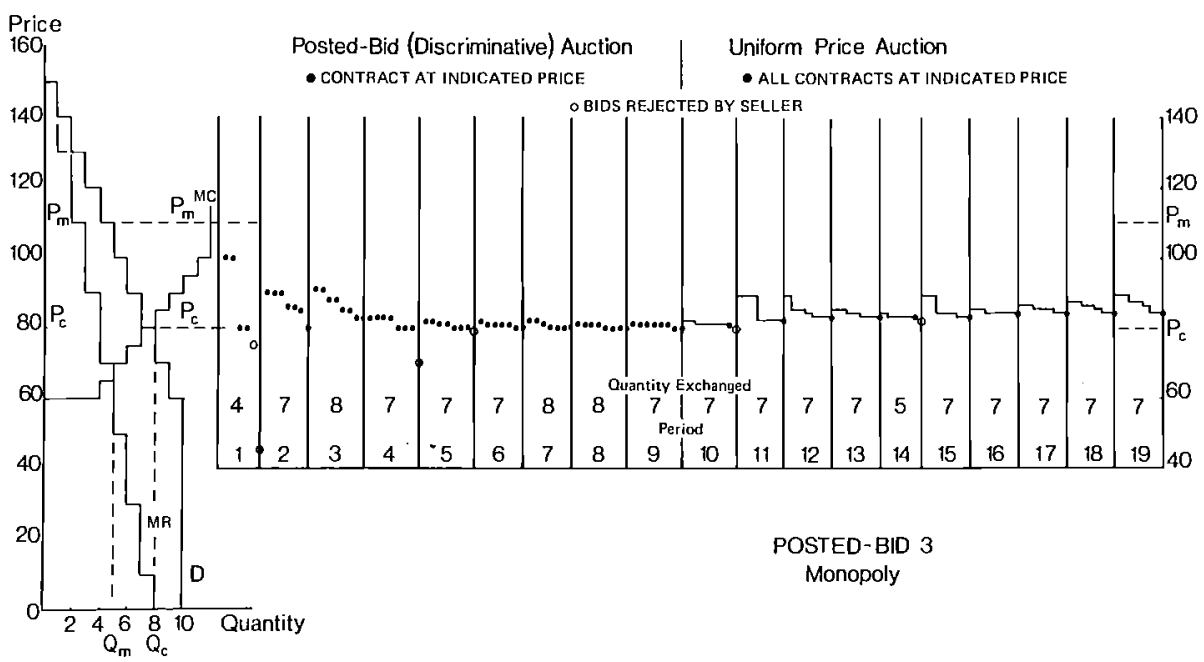

Fig. 8.

Initially in this experiment buyers independently select bids which are then posted by the experimenter from highest to lowest. The seller then selects a buyer (the highest bidder of course) and makes a quantity offer. The buyer responds with an acceptance of any part of that quantity except that the buyer is required to accept at least one unit. This specific take-it-or-leave-it pricing process has been referred to as the Posted-Bid institution and has been demonstrated (Plott \& Smith, 1978) to operate to the advantage of buyers. This is because the incentive of individual buyers to understate or underreveal their demand supports buyer "cooperative" efforts to coordinate with low bids. In view of this a question of substance is whether or not the Posted-Bid institution might serve as a means of decentralized control over monopoly pricing.

In Fig. 8 the first nine trading periods were under the Posted-Bid form of discriminative auction. In periods $1-9$ the bids plotted were also contract 
prices. The seller stabilized early in the delivery of seven or eight units against the bids tendered in each period while bid prices gradually converged toward the competitive price $\$ .80$. At the beginning of trial 10 it was announced that henceforth the seller could no longer sell units at different prices. When the bids were posted the seller first announced a cut-off bid price, then made offers successively to the buyers (in order) as before, but with the understanding that each would pay a price equal to the lowest bid accepted (indicated by the dot in periods 10-19 of Fig. 8) by the seller. As displayed in Fig. 8, the immediate effect of this change in the bidding institution produced an increase in the bids, and a gradual upward drift of the price level. It appears that the bids were converging slowly to the quantity-conditional competitive price $\$ .90$, i.e., the competitive price given that the seller was delivering seven units per period.

\subsection{Laboratory and Field Studies of Sealed-Bid Securities Markets}

An earlier experimental study (Smith, 1967) of the effect of discriminative and competitive pricing rules on bidding behavior was patterned after procedures used, and procedures proposed, in the auctioning of U.S. Treasury bills. In the experimental paradigm subjects bid for 18 units of a commodity whose resale price was determined, after the bids were tendered, by a drawing from a rectangular probability mass function whose parameters were known to the subjects. There were two experimental treatment conditions: the award rules and the number of bidders. Under the discriminative (D) award treatment the highest 18 bids were accepted at the bid prices specified. Under the competitive (C) treatment the highest 18 bids were accepted at the bid price specified by the lowest or 18 th bid. The number of subjects were 13 , 15 , and 17 in each of three pairs of experiments. Since each subject could tender two bids, and the offer quantity was always 18 units, the number of rejected or excess bids was 8,12 , and 16 in the three pairs of experiments. Hence the study consisted of six experiments in a $2 \times 3$ design with two levels for the bidding institution $(D, C)$ and three levels for the number of rejected bids $(8,12,16)$. In each experiment up to 10 successive auctions were performed to allow for learning and to study convergence under stationary conditions. Five independent subject groups participated in the six experiments. The D group with 13 subjects ( 8 rejected bids) participated in 8 auction periods, then the instructions for the $\mathrm{C}$ rules were introduced, and eight more auctions were performed. Hence the group wih 8 rejected bids participated in a D-C "switchover" experiment.

Figure 9 displays the bid distributions for each paired (D, C) set of experiments for trading periods $1,3-5$. The tendency for the $\mathrm{C}$ bid distributions to stochastically dominate the $\mathrm{D}$ bid distributions in the accepted 

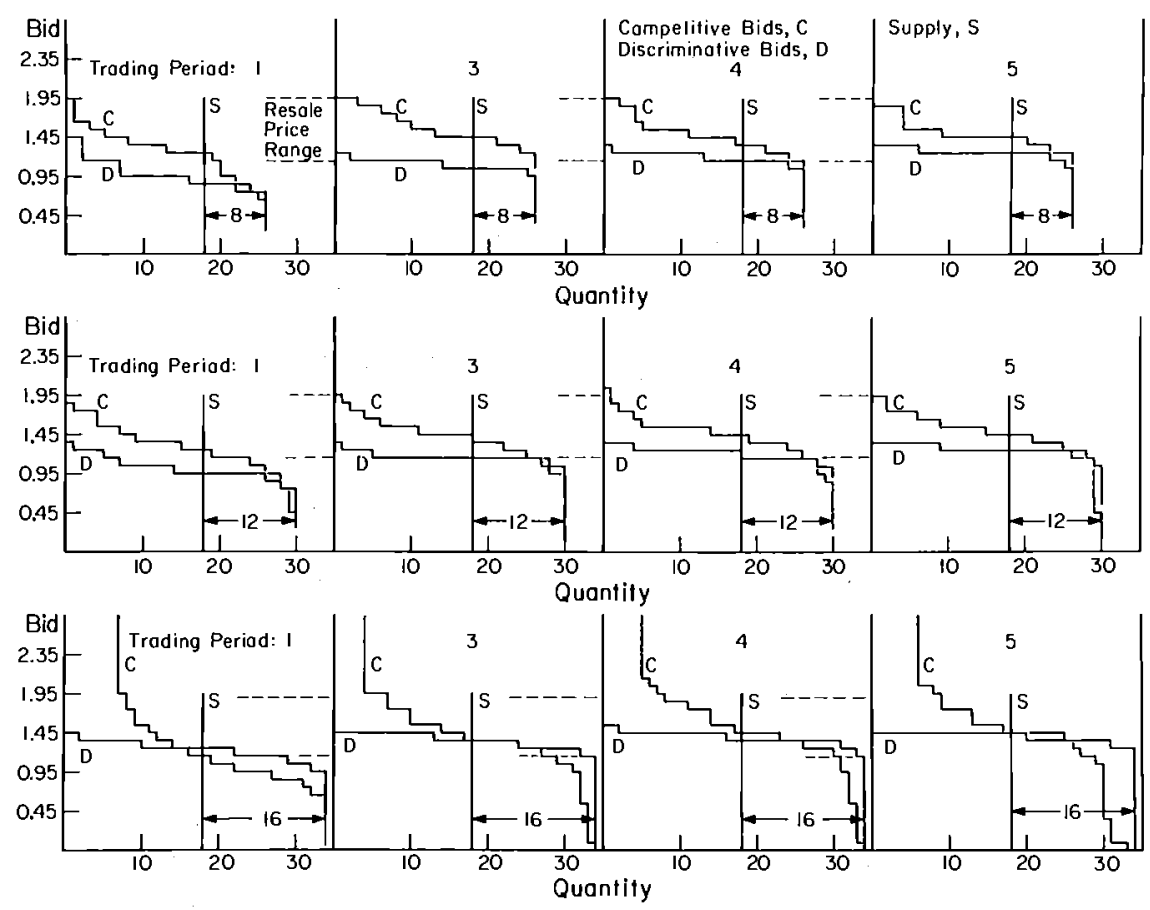

Fig. 9. [From Bidding and auctioning institutions: Experimental results by V. L. Smith. In Y. Ahimud (Ed.), Bidding and auctioning for procurement and allocation. New York: New York University Press, 1976. Chart 10, p. 61. Copyright (C) 1976 by New York University.]

bid range is obvious. Several hypotheses were tested leading to the following conclusions:

1. The variance of $\mathrm{C}$ bids is significantly greater than the variance of $\mathrm{D}$ bids, and this discrepancy increases as the number of rejected bids increases.

2. The distribution of accepted $\mathrm{C}$ bids is significantly higher than the distribution of accepted $\mathrm{D}$ bids for all rejected bid treatments. The proposition holds for all bids for $\mathrm{C}$ and $\mathrm{D}$ comparisons when there are 8 and 12, but not 16 , rejected bids.

3. The total receipts of the seller are greater in a $\mathrm{C}$ than in a $\mathrm{D}$ auction for 8 and 12 , but not for 16 , rejected bids. This suggests that the advantage to the seller of the $\mathrm{C}$ over the $\mathrm{D}$ bidding rules may disappear if there is a large enough number of rejected bids.

4. D auctions with a larger number of rejected bids tend to stochastically dominate $\mathrm{D}$ auctions with a smaller number of rejected bids. The proposition does not hold for Cauctions. This is consistent with the theoretical hypothesis that $\mathrm{C}$ auctions provide incentives for demand revelation while $\mathrm{D}$ auctions provide incentives to strategically underbid depending upon risk and ex- 
pectations which in turn can be supposed to be affected by the volume of rejected bids.

5. The total receipts of the seller are greater, the greater the number of rejected bids in a $\mathrm{D}$ auction. The proposition does not hold for $\mathrm{C}$ auctions.

6. An interesting behavioral characteristic of the $\mathrm{C}$ auctions is observable in Fig. 9. In every $\mathrm{C}$ experiment, for many auction periods, one or more subjects entered bids equal to or greater than the highest possible resale price in the domain of the resale distribution. Clearly, these subjects are bidding in excess of their marginal valuation for the item in order to be very sure of having their bid or bids accepted. This is a safe risk only if no more than 17 such bids are tendered.

Belovicz (1979) has replicated and considerably extended the preceding experimental research. Generally, his results and conclusions are consistent with the preceding ones, including the observation that $\mathrm{C}$ auction subjects sometimes bid in excess of marginal valuation.

At least three important developments in the marketing of securities have occurred since the above laboratory experiments were initiated. A modified version of the uniform-price competitive auction was adopted beginning in 1964 in the French marketing of new equity issues (McDonald \& Jacquillat, 1974). Beginning in January 1973 the Treasury auctioned six long-term bond issues using the low-bid uniform-price rule (Baker, 1976, p. 147). Finally in November, 1976, and again in April, 1977, Exxon Corporation took the unprecedented step of bypassing the normal underwriting institutions and marketing bond issues directly to registered broker-dealers using the low-bid uniform-price rule (Wall Street Journal, April 19, 1977). These developments are worthy of closer examination since they allow some comparisons to be made between the results of the laboratory experiments and the results of these "experiments" with new securities marketing institutions.

The French sealed-bid auction of new equity issues appears (by one criterion) to be a very successful institution. As of 1974 (McDonald \& Jacquillat, 1974, p. 40) no initial equity issue since 1964 had failed to receive sufficient bids to clear the quantity offered at the minimum price or higher. In this auction the issuing company states a minimum acceptable price in advance. When the bids are tendered a committee of company directors, their bankers, and officials of the Paris Bourse examine the computer printout of bids ranked from highest to lowest. Since orders to bid "at market" are not admissible, the committee rejects bids above some arbitrary level as "disguised market orders." It then allocates shares on a pro rata basis so that the offering is exhausted at a bid price slightly below that which they think can be sustained by free trading in the aftermarket (McDonald \& Jacquillat, 1974, pp. 41-42). The key point is that on a typical offering many 
French investors tender bids that are obviously more than their marginal valuations just as do their counterparts in the experimental laboratory. Stand-out behavioral characteristics such as this provide important evidence on parallelism (McDonald \& Jacquillat, 1974, p. 39, also note this similarity between investor and subject behavior).

In reporting on the results of the Treasury uniform-price auctions, Baker (1976) emphasizes the difficulty of being sure that differences in auction results are attributable to the auction form when the issues are of differing maturities and of different sizes. Considering all this, Baker (1976, p. 150) reports tentatively that there does appear to be some outward shift in the demand curve and the possibility of a small cost saving to the Treasury by pricing with the uniform-price auction.

Tsao \& Vignola (1977) have written a preliminary report of their study comparing the U.S. Treasury's auctioning of ten long-term bond issues under discriminative rules, with the auctioning of six long-term issues under the uniform-price rules. Table 2 provides some evidence on parallelism between laboratory and field experiments by comparing the preliminary results of Tsao \& Vignola (1977) for Treasury bond auctions with the results of the laboratory experiments reported by Smith (1967) and Belovicz (1979).

TABLE 2

COMPaRISON OF COMPETITIVE AND Discriminative auction Results Using Laboratory and Treasury Data

\begin{tabular}{lcc}
\hline Null hypothesis & $\begin{array}{c}\text { Test results, } \\
\text { laboratory experiments }\end{array}$ & $\begin{array}{c}\text { Test results, }{ }^{a} \text { nondealer bids, } \\
\text { Treasury's } 6 \text { competitive and } \\
10 \text { discriminative bond auctions }\end{array}$ \\
\hline $\begin{array}{c}\text { A. Variance of bids same } \\
\text { under C and D }\end{array}$ & $\begin{array}{c}\text { Reject in favor of } \\
V_{\mathrm{C}}>V_{\mathrm{D}}\end{array}$ & Reject in favor of $V_{\mathrm{C}}>V_{\mathrm{D}}$ \\
\hline $\begin{array}{c}\text { B. Mean bid same under } \\
\text { C and D . }\end{array}$ & $\begin{array}{c}\text { Reject in favor of } \\
\bar{B}_{\mathrm{C}}>\bar{B}_{\mathrm{D}}\end{array}$ & Reject in favor of $\bar{B}_{\mathrm{C}}>\bar{B}_{\mathrm{D}}$ \\
\hline $\begin{array}{c}\text { C. Mean bid independent of } \\
\text { volume of rejected bids } \\
\text { under C }\end{array}$ & Cannot reject & Reject \\
\hline $\begin{array}{c}\text { D. Mean bid independent of } \\
\text { volume of rejected bids } \\
\text { under D }\end{array}$ & Reject & Cannot reject \\
\hline $\begin{array}{c}\text { E. Seller revenue same under } \\
\text { C and D }\end{array}$ & $\begin{array}{c}\text { Reject in favor of } \\
R_{\mathrm{C}}>R_{\mathrm{D}} \text { in } 5 \text { of } 15 \\
\text { paired comparisons }\end{array}$ & $\begin{array}{c}\text { Reject in favor of } R_{\mathrm{C}}>R_{\mathrm{D}} \\
\text { in } 6 \mathrm{C} \text { auctions } \\
\text { and } 10 \mathrm{D} \text { auctions }\end{array}$ \\
\hline
\end{tabular}

\footnotetext{
${ }^{a}$ Based on preliminary report of Tsao and Vignola (1977).
} 
Conclusion 1 that the variance of $\mathrm{C}$ bids exceeds the variance of $\mathrm{D}$ bids holds also in the Treasury bond data. Conclusion 2 that the mean of $\mathrm{C}$ bids exceeds the mean of $\mathrm{D}$ bids holds for all bids, not just the subset of accepted bids, and for all proportions of rejected bids in the Treasury data. Conclusion 3 that seller receipts are greater in C than in D auctions holds for all proportions of rejected bids in the Treasury data. Finally, conclusion 4 is strangely reversed in the Treasury data, i.e., C auctions with a larger proportion of rejected bids tend to stochastically dominate $\mathrm{C}$ auctions with a smaller proportion of rejected bids. The proposition does not hold for $D$ auctions. This reversal is directly contrary to what one would expect from the theory and suggests the need for further replication of the laboratory experiments to determine if there is anything artifactual about the original results.

Apparently the management of Exxon Corporation is satisfied that the uniform-price auction yields a net savings to the corporation's financing operations. In May 1977 Exxon guaranteed a \$250 million issue of 30 year tax exempt bonds offered by the city of Valdez, Alaska, the proceeds to be used by Exxon Pipeline Co. This is the second such offering of Exxon guaranteed bonds under the uniform-price auction, and the company indicated that it may soon offer its own debt obligations by this procedure (Wall Street Journal, April 19, 1977, p. 31). The results of the second issue provided bid tenders for over one billion dollars, or about four times the quantity offered, giving a price of $\$ 985.82$ per $\$ 1000$ face amount of bonds, with a coupon rate of $5 \frac{1}{2} \%$, to yield $5.598 \%$. The yield equivalent of all the bids ranged from $5 \%$ to $5.88 \%$ (Rickert, 1977 ).

\section{Choice Mechanisms for Public Goods}

In this section we shall review one laboratory and two field experiments designed to test or compare decentralized decision mechanisms for public goods.

\subsection{The Auction Mechanism for Public Goods}

The first set of experiments to be reviewed applies the Auction Mechanism (Smith, 1979) to a collective's choice of the quantity of a pure public good. The experimental design is based on a partial equilibrium (no income effects) version of the mechanism. In this mechanism, let $V_{i}(X)$ be the dollar value to $i$ of $X$ units of a common outcome public good that can be purchased by a collective of $I$ members at a price $q$. Let each $i$ submit a two-tuple 
$\left(b_{i}, X_{i}\right)$, where $b_{i}$ represents member $i$ 's contribution per unit of the public good toward its purchase, and $X_{i}$ is the quantity of the public good that $i$ proposes for collective purchase. In the experimental setting $V_{i}(X)$ is used to induce value on $X$ for each $i$. If $i$ 's utility of money is $U_{i}(\cdot)$, and we let $u_{i}$ be $i$ 's final outcome utility, then the Auction Mechanism-yietds

$$
u_{i}=\left\{\begin{array}{cl}
U_{i}\left[V_{i}(\bar{X})-\left(q-\sum_{j \neq i} b_{j}\right) \bar{X}\right] \quad \text { if } \quad b_{i}=q-\sum_{j \neq i} b_{j} \\
\text { and } \\
\\
X_{i}=\bar{X}=\sum_{k=1}^{I} X_{k} / I \text { for all } i \\
U_{i}(0)=0 \quad \text { if } \quad b_{i} \neq q-\sum_{j \neq i} b_{j} \\
\\
\text { or } \\
X_{i} \neq \bar{X} \text { for any } i .
\end{array}\right.
$$

The collective's proposed quantity of the public good is defined as the mean, $\bar{X}$, of the individual proposals, while the collective's allocation of unit cost to $i$ is $q-\sum_{j \neq i} b_{j}$. Collective agreement occurs if every $i$ agrees to accept his share of cost by bidding $b_{i}=q-\sum_{j \neq i} b_{j}$ and agrees to accept the group's proposal by proposing $X_{i}=\bar{X}$. Otherwise none of the public good is purchased and no $i$ enjoys the potential surplus from the public good.

That the mechanism defined by (1) provides incentives for optimal collective decision is shown by selecting $\left(b_{i}, X_{i}\right)$ to maximize $U_{i}$. Maximization requires $i$ to choose $\left(b_{i}, X_{i}\right)$ so that $U_{i}^{\prime}(\cdot)\left[(1 / I) V_{i}^{\prime}(\bar{X})-\left(q-\sum_{j \neq i} b_{j}\right)(1 / I)\right]=0$, but also to choose $b_{i}=q-\sum_{j \neq i} b_{j}$ and $X_{i}=\bar{X}$ to avoid vetoing the arrangement. If $U_{i}^{\prime}>0$, then $V_{i}^{\prime}(\bar{X})=q-\sum_{j \neq i} b_{j}=b_{i}$, and since $b_{i}+\sum_{j \neq i}^{I} b_{j}=$ $\sum_{k=1}^{I} b_{k}=q$, summing over all members gives $\sum_{i=1}^{I} V_{i}^{\prime}(\bar{X})=q$. Hence $X=$ $X^{0}$, where $X^{0}$ is the Lindahl (and Pareto) optimal quantity of the public good.

Two comments on this mechanism refer respectively to its relevancy and its behavioral interpretation:

(1) This mechanism is simply a generalization of a very common private institution for the provision of a public good. Whenever a religious, art, or music society attempts to obtain a new church, museum, or music hall by canvassing its members (and, often, nonmembers) for contributions, the society is effectively using a discrete version of the Auction Mechanism. That is, the new facility is purchased if and only if contributions equal or exceed the cost of the facility. 
(2) The Auction Mechanism has important behavioral similarities to the Vickrey-Marschak Second Price auction and to the uniform-price multiunit auction. In these auctions the price paid by the buyer is determined directly by the actions of other buyers. One is awarded a unit only if his bid "beats" the first rejected bid. Similarly, in the Auction Mechanism for public goods agent $i$ 's unit cost allocation $q-\sum_{j \neq i} b_{j}$ is determined by all $j \neq i$. If $i$ can and does bid high enough to accept this share of cost, then $i$ is able to enjoy the surplus attainable from the public good.

Twelve experiments (Smith, 1979) have been conducted using the mechanism described above (see Table 3). The experimental process consisted of a series of trials with a specified upper limit $T$ to the number of trials allowable. The stopping rule for determining collective agreement was for each subject to bid his share of cost on two successive trials $\left(t^{*}-1, t^{*}\right)$, and to accept the group's proposal on the final "stop" trial $\left(t^{*}\right)$. Each trial began with each subject privately choosing $\left(b_{i}, X_{i}\right)$, and ended with the public posting of $\sum_{k=1}^{I} b_{k}$ and $\bar{X}$ which enables each subject to compute $q-\sum_{j \neq i} b_{j}=q-$ $\left(\sum_{k=1}^{I} b_{k}-b_{i}\right)$ and determine his "profit" $V_{i}(\bar{X})-\left(q-\sum_{j \neq i} b_{j}\right) \bar{X}$ on that trial.

Table 3 summarizes the results of three experimental sessions (Al) with $I=5$, five sessions (A2) with $I=4$, and four sessions (A3) with $I=8$. The A3 sessions were a replication of the $\mathrm{A} 2$ but with two subjects rather than one having the valuation functions $V_{i}(X), i=1,2,3,4$, and with the price of the public good twice its level in A2. This permitted an examination of the effect of doubling the size of the collective while keeping constant the relative structure of taste and cost. Table 3 records the Lindahl prices and quantity for each experimental design ${ }^{6}$ and the actual final bids and quantities for each experimental session. Only session A3.2 failed to reach agreement for reasons clearly attributable to incentive incompatibility (or "free riding"). Four of the sessions (A1.2, A2.1, A2.3, and A3.2) encountered coordination problems associated with the stopping rule. That is, in these sessions the cost of the public good was either overbid or agreement was within one bid unit with one or more subjects hesitant to fill in the bid gap for fear of an overbid. (In recent experiments this problem has been solved by rebating any overbid to each subject in proportion to his bid and modifying the process to allow the collective simply to vote at the end of each trial for which the cost of the public good is covered. Agreement then requires a unanimous vote in favor of finalizing the outcome of that trial.)

By estimating the parameters of the regression equation $b_{i}=\beta_{0}+\beta p_{i}$ where $p_{i}$ is the Lindahl price and $b_{i}$ the final bid for subject $i$ one may test

\footnotetext{
${ }^{6}$ See Smith (1979) for a complete presentation of the experimental design parameters, instructions, and results.
} 


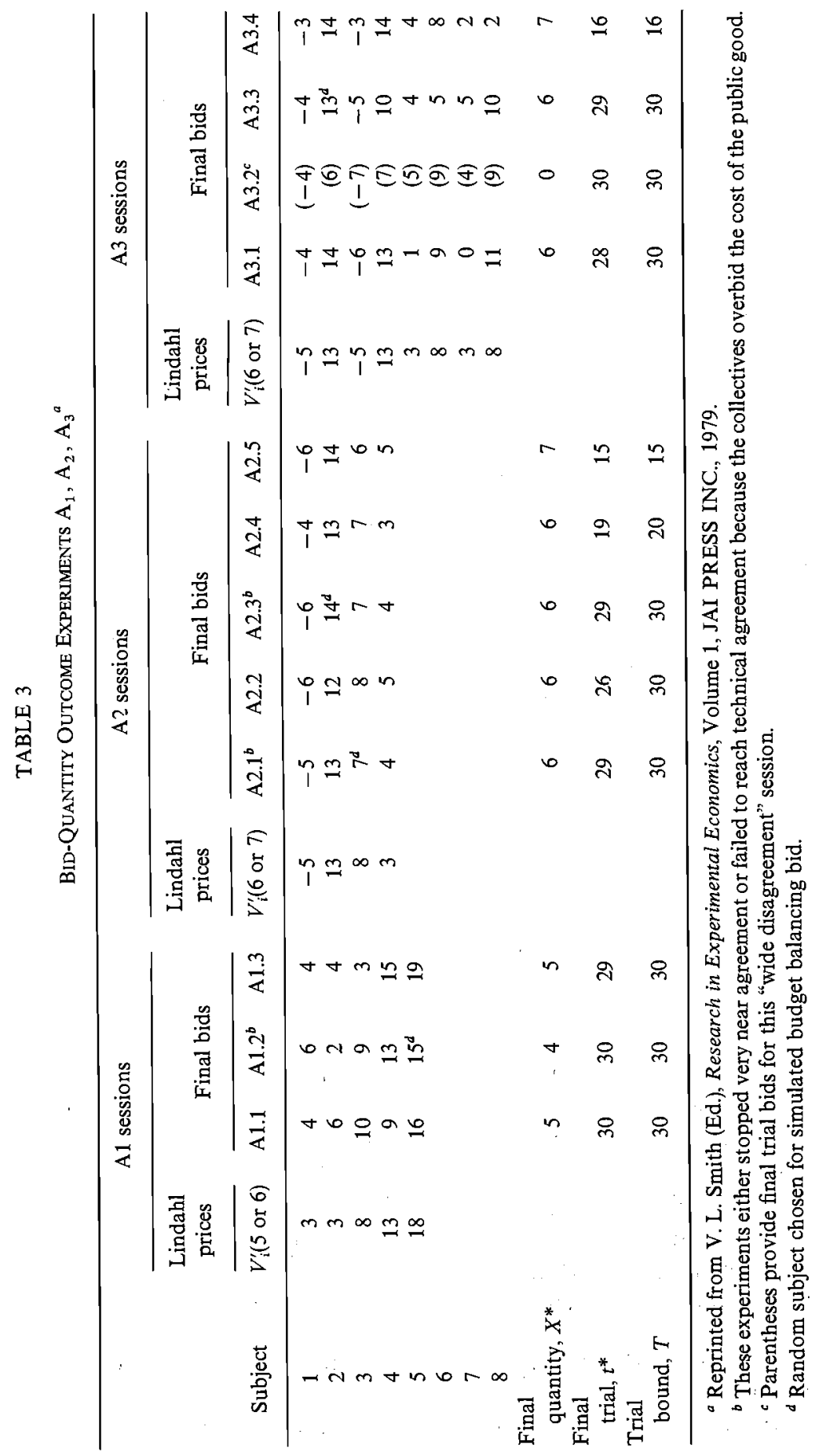


the hypothesis that the theoretical Lindahl prices explain subject bids. The results (Smith, 1979) yield $R^{2}$ from 0.82 to 0.99 across the three sets of experiments, with $\widehat{\beta}_{0}$ not significantly different from zero and $\hat{\beta}$ not significantly different from unity.

These experiments provide rather encouraging evidence to suggest that small collectives can voluntarily provide Lindahl public good equilibria. Of course one observes this whenever a fund drive by a private society ends successfully, but in such nonlaboratory environments one does not observe individual valuations. Hence there is no way of relating success or nonsuccess to valuations to examine the efficiency of the mechanism.

\subsection{BOHM EXPERIMENT}

In a Swedish experiment (Bohm, 1972) consumers (who had volunteered to come to a TV studio for a payment of $\mathrm{Kr}$. 50) were randomly assigned to six different groups and asked to state how much they were willing to pay under six different cost sharing rules to watch a particular TV program that had not yet been shown to the public. The sixth group made hypothetical choices while for the remaining five the program would be shown if and only if the aggregate of the amount offered were sufficient to cover the cost. Each group was led to believe that there were parallel groups in other rooms whose responses were to be merged with theirs. In this way a group, for example of size 23 (treatment I), would find it credible that with offers of only several $\mathrm{Kr}$. each the program cost (Kr. 500) was covered. Unknown to the subjects, the program was to be shown whatever the amount of the offer.

Among the various experimental groups the amounts each consumer paid, conditional on the aggregate amount offered exceeding cost, were as follows (the mean offer in $\mathrm{Kr}$. appears in parentheses):

I. The amount stated (Kr. 7.61).

II. A percentage of the amount stated, normalized so that cost is just covered (Kr. 8.84).

III. Either the amount stated, a percentage of this amount, $\mathrm{Kr}$. 5, or nothing, to be determined by a lottery (Kr. 7.29).

IV. Kr. 5 (Kr. 7.73).

V. Nothing. The costs would be paid by the broadcasting company, i.e., out of general taxes (Kr. 8.78).

VI. Nothing. The response was hypothetical (Kr. 10.19).

According to Bohm's analysis only treatment VI led to offers which differed to any (classically) significant degree from the others. Several interpretations and observations seem relevant to this experiment: 
1. Treatment I corresponds to the Auction Mechanism applied to an indivisible public good. The theory discussed previously suggests that there are strong incentives for revealing demand under this mechanism and from our experiments we have evidence that in the context of an iterative process this mechanism produces incentive compatible outcomes. Consequently, notwithstanding the conventional wisdom on public goods, Bohm's treatment I should not be expected to yield strong free-rider tendencies unless this is a peculiarity of single trial responses. The theory that has maintained that free-riding will occur in this context has not taken account of the opportunity losses incurred by failure to cover cost.

2. Irrespective of these considerations, if treatment $I$ is regarded as the "free-rider" control experiment against which comparisons are made, then the effect of each of the treatments II, IV, V, and VI is to raise the average offer in what might be considered the expected direction. That is, subjects might be expected to offer more in II than in I in the expectation that their share of cost in II is unlikely to exceed that in I. Similarly, IV provides a modest fixed imputation of the cost regardless of one's offer, and similarly for V and VI.If the preexperimental hypothesis had been that these were the directions in which the treatment outcomes would diverge, then regardless of the significance tests by classical standards, one would have to conclude that the experimental results increased to some degree the credibility of the hypothesis.

3. The lower offers elicited under treatment III are not in accordance with expectations based upon the above arguments. However, treatment III is by far the most complex or ambiguous, psychologically. The lower average offer in III is consistent with the "ambiguity hypothesis" which would assert that where outcomes are defined by psychologically "rich" (complicated, mysterious, uncertain) processes, subjects are more conservative, or cautious, in their responses. This phenomenon is suggested in a somewhat different context (Ellsberg, 1961; Sherman, 1974) but may have application in the Bohm experiment.

4. Each subject was asked for a single response. Although the subjects "accepted the question as ... posed and (most) ... gave their responses in a matter of a minute or less (Bohm, 1972, p. 126)," the result is not likely to be the same as would obtain if the subjects arrived at a final decision through a process involving many response-outcome iterations.

\subsection{The PBS Station Program Cooperative}

In 1974 the Public Broadcasting Service began a three-year experiment to develop a decentralized process for the selection of programs to be broadcast over the noncommercial television network. Some results of the first 
two seasons of experience with this Station Program Cooperative (SPC) have been reported by Ferejohn \& Noll (1976). Approximately 150 participating stations made actual selections from 93 programs in the first experiment and 136 in the second. The process consisted of 12 iterations (with each station manager communicating through his teletypewriter) and converged rapidly (in 7 iterations) to 25 produced programs the first year and (in 10 iterations) to 38 produced programs the second year. The cost of program $j$ for station $i$ on trial $t$ was

$$
C_{j}\left[\frac{0.8 b_{i}}{B_{j}(t-1)}+\frac{0.2 n_{i}}{N_{j}(t-1)}\right],
$$

where $C_{j}$ was the producer's cost of program $j, b_{i}$ is the budget and $n_{i}$ the population served for any station $i$ selecting program $j$, and $B_{j}(t-1)$ is the aggregate budget and $N_{j}(t-1)$ the aggregate population served for all stations selecting program $j$ on trial $t-1$.

This cost sharing rule has the essential features of the Auction Mechanism, i.e., (1) each manager risks forfeiting his private net benefit if he fails to "vote for" a program, and (2) he has veto power over the cost allocated to him by the choices of all other stations. However, it has the undesirable characteristic that stations can only accept or reject a program at a bid determined mechanically by the above formula. A station willing to pay some amount for a particular program, but less than the formula allocation, must perforce decline to select the program, while a station willing to pay more than its formula allocation has no way of signaling this intensity by increasing its bid. But these are obvious armchair criticisms that may or may not be operationally significant. One must take seriously a mechanism that yields large scale allocations judged to be satisfactory by the participating agents.

\section{Conclusion}

This paper has been mute in its reference to the theme of this conferencethe evaluation of econometric models. This is because the message of the paper calls for us to start over in resource allocation theory and in the econometric modeling of microeconomic phenomena. There is no conflict between the scientific objectives of econometric modeling and experimental methodology. Indeed, it is questionable whether or not econometrics can be given any scientific content whatsoever in the absence of experimental data and replication. 
The problem with any attempt to provide econometric models of market behavior (laboratory or nonlaboratory) is that we simply do not have any adequate theory. Competitive price theory requires that there be such a large number of buyers and sellers that each effectively becomes a price taker. Yet experimental markets with as few as 3-4 buyers and as many sellers converge with astonishing rapidity to within a narrow range of the supply and demand equilibrium using the double auction institution in which every participant is a price maker not a price taker. Furthermore, these results can be modified in experiments that alter the rules governing the institution of contract; for example, by allowing only sellers to make quotations or by requiring sellers to post take-it-or-leave-it offers. But to date we have no theory of price formation under these alternative institutions that lends itself to econometric modeling. Economic theorists sometimes suggest that complete information on supply and demand is sufficient, if not necessary, to the attainment of a competitive equilibrium. Yet, as we have seen above, there are experimental supply and demand configurations in which convergence to the competitive equilibrium is weakened by the state of complete information. This suggests that economic theory seriously lacks an adequate treatment of the role of information in price adjustment processes.

In short, we have no theory of price adjustment processes or institutions that is operational enough to allow an econometric modeling of experimental markets. The traditional ad hoc difference-differential equation dynamics does not deal with process. The literature on price search theory appears to be dealing with the appropriate ingredients of a satisfactory theory, but as yet this work is still based on too simplistic a set of assumptions to capture the search-learning process that seems to characterize institutions such as the double auction.

Yet the challenge to theory unmistakable; there is a growing body of hard laboratory results based on numerous replications and a great diversity of price-making institutions. Furthermore, the studies by Bohm (1972) and Ferejohn \& Noll (1976) for public goods, and by Tsao \& Vignola (1977) for private goods suggest that models of laboratory behavior have direct relevance to the modeling of field behavior. ${ }^{7}$ What is needed is a restructuring of theory to capture the institutional elements in the price formation process, whether the theory is to be tested with laboratory experiments or field data. In this paper we argue that we ought to begin with the laboratory results where value (cost) is induced, and hence an important extraneous source of variability is controlled.

${ }^{7}$ That is, these field studies report many results that are consistent with the results of laboratory experiments such as those reported by Smith $(1967,1979)$ and Belovicz (1979). 


\section{ACKNOWLEDGMENTS}

I am grateful to the National Science Foundation for research support and to Raymond Battalio, John Kagel, and Charles Plott for many valuable discussions and comments.

\section{REFERENCES}

Arrow, K. Price-quantity adjustments in multiple markets with rising demands. In K. Arrow, S. Karlin, and P. Suppeo (Eds.), Mathematical methods in the social sciences. Stanford, Cal.: Stanford Univ. Press, 1960. Ch. 1, Pp. 3-15.

Arrow, K., \& Capron, W. Dynamic shortages and price rises: The engineer-scientist case. Quarterly Journal of Economics, 1959, 75(May), 292-308.

Baker, C. Auctioning coupon bearing securities: A review of Treasury experience. In Y. Amihud (Ed.), Bidding and auctioning for procurement and allocation. New York: New York University Press, 1976. Pp. 146-154.

Battalio, R., Kagel, J., Winkler, J., Fisher, R., Basmann, R., \& Krasner, L. A test of consumer demand theory using observations of individual purchases. Western Economic Journal, 1973, 11(December), 411-428.

Belovicz, M. Sealed-bid auctions: Experimental results and applications. In V. L. Smith (Ed.), Research in experimental economics. Vol. 1. Greenwich, Conn.: JAI Press, 1979, Pp. 279 338.

Bohm, P. Estimating demand for public goods: An experiment. European Economic Review, $1972,3,111-130$.

Carlson, J. The stability of an experimental market with a supply-response lag. The Southern Economic Journal, 1967, 33(January), 299-321.

Ellsberg, D. Risk, ambiguity, and the Savage axioms. Quarterly Journal of Economics, 1961, 75(November), 643-669.

Ferejohn, J., \& Noll, R. An experimental market for public goods: The PBS Station Program Cooperative. American Economic Review, Papers and Proceedings, 1976, 66(May), 267273.

Fiorina, M., \& Plott, C. Committee decisions under majority rule: An experimental study. Social Science Working Paper \# 101, California Institute of Teclınology, December 1975.

Fouraker, L. E., \& Siegel, S. Bargaining behavior. New York: McGraw-Hill, 1963.

Hess, A. C. Experimental evidence on price formation in competitive markets. Joumal of Political Economy, 1972, 80(March/April), 375-385.

Leibenstein, H. Beyond economic man. Cambridge, Mass.: Harvard Univ. Press, 1976.

Marschak, J. Statistical inference in economics: An introduction. In T. C. Koopmans (Ed.), Statistical inference in dynamic economic models. New York: Wiley, 1950. Pp. 1-50.

Marschak, J. Economics of inquiring, communicating, deciding. American Economic Review, Papers and Proceedings, 1968, 58(May), 1-18.

McDonald, J., \& Jacquillat, B. Pricing of initial equity issues: The French sealed-bid auction. Journal of Business, 1974, 47(January), 37-52.

Miller, R., Plott C., \& Smith, V. Intertemporal competitive equilibrium: An empirical study of speculation. Quarterly, Journal of Economics, 1977, 91(November), 599-624.

Plott, C. The application of laboratory experimental methods to public choice. Social Science Working Paper \#223, California Institute of Technology, July 1978.

Plott, C., \& Levine, M. A model of agenda influence on committee decisions: American Economic Review, 1978, 68(March), 146-160. 
Plott, C., \& Smith, V. An experimental examination of two exchange institutions. Review of Economic Studies, 1978, 45(February), 133-153.

Rickert, L. B. Tax-exempt prices skid as supply rises: Exxon issue part of $\$ 1$ billion deluge. Wall Street Journal, May 4, 1977, p. 31.

Samuelson, P. Intertemporal price equilibrium: A prologue to the theory of speculation. Weltwirtschaftliches Archiv, 1957, 79(2), 181-219.

Samuelson, P. Economics. (9th ed.) New York: McGraw-Hill, 1973.

Shapley, H. Of stars and men. Boston: Beacon Press, 1964.

Sherman, R. The psychological difference between ambiguity and risk. Quarterly Journal of Economics, 1974, 88(February), 166-169.

Shubik, M. Strategy and market structure. New York: Wiley, 1959.

Smith, V. L. Effect of market organization on competitive equilibrium. Quarterly Journal of Economics, 1964, 78(May), 181-201.

Smith, V. L. Experimental studies of discrimination versus competition in sealed-bid auction markets. Journal of Business, 1967, 40(January), 56-84.

Smith, V. L. Experimental economics: Induced value theory. American Economic Review Papers and Proceedings, 1976, 66(May), 274-279. (a)

Smith, V. L. Bidding and auctioning institutions: Experimental results. In Y. Amihud (Ed.), Bidding and auctioning for procurement and allocation. New York: NY Univ. Press, 1976. Pp. 43-64.(b)

Smith, V. L. Incentive compatible experimental processes for the provision of public goods. In V. L. Smith (Ed.), Research in experimental economics. Vol. 1. Greenwich, Conn.: JAI Press, 1979. Pp. 59-169.

Tsao, C., \& Vignola, A. Price discrimination and the demand for Treasury's long term securities. Preliminary report circulated privately, 1977.

Vickrey, W. Counterspeculation, auctions, and competitive sealed tenders. Journal of Finance, 1961, 16(March), 8-37.

Wall Street Journal. Exxon plans to use "Dutch" auction again to sell a $\$ 250$ million taxexempt issue. April 19, 1977, p. 31.

Williams, A. Intertemporal competitive equilibrium: Further experimental results. In V. L. Smith (Ed.), Research in experimental economics. Greenwich, Conn.: JAI Press, 1979. Pp. 255-278. 